\title{
Combination of ICP-OES, XRF and XRD techniques for analysis of several dental ceramics and their identification using chemometrics
}

\author{
Safwan M. Obeidat ${ }^{\mathrm{a}, *}$, Idrees Al-Momani ${ }^{\mathrm{a}}$, Asma'a Haddad ${ }^{\mathrm{a}}$ and Motasem Bani Yasein ${ }^{\mathrm{b}}$ \\ ${ }^{a}$ Chemistry Department, Yarmouk University, Irbid, Jordan \\ ${ }^{\mathrm{b}}$ Bani Yasein Dental Laboratories, Irbid, Jordan
}

\begin{abstract}
In this paper dental ceramic samples from seven vendors were studied. The elemental composition for each type was investigated using the ICP-OES and the XRF. Assessment of the seven types of ceramic was also successfully achieved using the XRD spectral data and processed with Principal Component Analysis (PCA). Detecting possible adulteration in different mass percentages of ceramic was also possible by applying the XRD data for the adulterated samples to the original PCA model.
\end{abstract}

Keywords: Dental ceramics, ICP-OES, XRF, XRD, PCA

\section{Introduction}

The word Ceramic is derived from the word Keramos in Greek which means pottery [7]. According to the American Ceramic Society, ceramic is defined as inorganic, nonmetallic materials, which are typically crystalline in nature. In general dental ceramics can be classified into categories based on several properties. One common classification is based upon the chemical composition of these ceramics. In this classification the most traditional type of ceramic is feldspar-based that contains silica glasses. Feldspar-based ceramics are also known as 'Silica-Based Ceramics' [4]. Another type of ceramics which contain a relatively large crystalline phase that helps stop crack growth is called glass ceramics. This type has higher fracture toughness than traditional feldspar-based ceramics [4]. To improve the toughness of dental ceramics even better high strength core ceramics was mainly developed. This was achieved via combining the feldspar-based ceramics with a metallic substructure such as alumina and zirconia in the crystalline matrix. More details on these types can be found in [4]. The use of ceramic in dentistry is due to many properties such as biocompatibility, aesthetics and durability in addition to all that ease of fabrication of complex shapes and sufficient mechanical and corrosion resistance [2,3,8,11]. Nowadays several dental ceramic suppliers are present in the market all over the world. Many of these commercial dental ceramics from different producers were studied. However, most of these studies concentrated on the physical properties of the ceramic $[5,6,10,12]$, while only few studies deals with the chemical

\footnotetext{
*Corresponding author. Fax: +11 9622721 1117; E-mail: Safwan@yu.edu.jo.
} 
composition of ceramics [8]. In addition, to the best of our knowledge, there are no studies discriminate among the different types of dental ceramics available in market and hence detecting possible adulterated samples that might compose of two types of ceramic has not been reported in the literature. Due to the gap in price and quality of these ceramics we believe that an assessment of these types based on chemical or physical properties is highly demanded especially in the absence of visual or simple procedures to identify different types of dental ceramics. The presence of a reliable assessment technique will also help in detecting adulteration even if different ceramic types were mixed together to take advantage of the price difference. In this study ceramic samples from seven different vendors were obtained and given the codes (A, B, D, H, G, F and S). Six ceramic samples from each vendor were investigated. To study the elemental composition of these ceramic types they were analyzed using both the ICP and the XRF. For the purpose of assessment of these ceramic types the spectra of XRD for all ceramic samples were collected and compared using Principal Component Analysis (PCA) algorithm.

\section{Experimental section}

\subsection{Materials and solutions}

Dental ceramic samples from seven vendors in seven different countries were obtained directly from the exclusive importers in Jordan, Syria and Lebanon. Six samples from each type were obtained. The total number of samples was 42 (6 samples from each of the 7 vendors). ICP-OES and XRF were used to study chemical composition of these samples. XRD spectral data for the ceramic samples were used to create a PCA calibration model. Mixtures between relatively highly priced and less expensive types of the above ceramic types were created in our laboratories. These mixed samples represent adulterated samples. Two mass ratio compositions of each mixture were prepared and studied. The description and the composition of these mixtures are shown in Table 1. Samples were mixed using a vortex mixer for about six hours. Mixture samples were investigated by XRD solely.

\subsection{ICP-OES}

Approximately $0.30 \mathrm{~g}$ of the ceramic powder of each sample was accurately weighed and carefully transferred into a clean 50-ml Teflon (PTHF) beaker. Afterward, $5.0 \mathrm{ml}$ of concentrated redistilled grade nitric acid were added to each sample. The powder and the beaker were swirled regularly to ensure that all of the powder was wetted. The beakers were kept covered and left for $3 \mathrm{~h}$ at room temperature. Ten milliliters of hydrofluoric acid were added and the mixtures were refluxed while beakers kept covered for about five hours until complete digestion of the samples. When the mixtures become clear, the covers were removed and the acids were slowly evaporated to near dryness. At this stage, $2 \mathrm{ml}$ of the concentrated nitric acid were added and the solutions were re-evaporated again to about $1.0 \mathrm{ml}$. The digests were cooled and diluted with deionized water up to $25 \mathrm{ml}$ in a volumetric flask and stored in plastic bottles. A Varian Vista-MPX CCD simultaneous ICP-OES with axially viewed plasma was used for the analysis of samples. Calibration solutions were made daily by serial dilution of commercially available multi-element standards. To ensure data quality, blank samples of acids were prepared in exactly the same manner as the test samples and analyzed. These concentration values were subtracted from digested samples. In addition, drift correction was done by running a set of standards before and after the ICP-AES analysis of the samples. Wavelength calibration was also made before starting by using a special wavelength calibration solution prepared for this purpose. 
Table 1

The identity of all ceramic samples, their composition and producer

\begin{tabular}{lcccc}
\hline Sample ID & Price & Composition by mass & Producer/country & Sintering temperature $\left({ }^{\circ} \mathrm{C}\right)$ \\
\hline A & High & - & Vita/Germany & 900 \\
B & High & - & Ivoclar/Swaziland & 870 \\
D & Low & - & Noritake/Japan & $930-940$ \\
F & Low & - & Creation/Austria & 770 \\
G & High & - & Alphadent/Korea & 920 \\
H & Low & - & Elephant/Netherlands & 890 \\
S & Low & - & - & 895 \\
GH1 & - & $70 \%$ G: $30 \% \mathrm{H}$ & - & - \\
GH2 & - & $35 \% \mathrm{G}: 65 \% \mathrm{H}$ & - & - \\
GF1 & - & $70 \% \mathrm{G:} 30 \% \mathrm{~F}$ & - & - \\
GF2 & - & $35 \% \mathrm{G:} 65 \% \mathrm{~F}$ & - & - \\
AF1 & - & $70 \% \mathrm{~A}: 30 \% \mathrm{~F}$ & - & - \\
AF2 & - & $35 \% \mathrm{~A}: 65 \% \mathrm{~F}$ & - & - \\
AH1 & - & $70 \% \mathrm{~A}: 30 \% \mathrm{H}$ & - & - \\
AH2 & - & $35 \% \mathrm{~A}: 65 \% \mathrm{H}$ & - & - \\
BD1 & - & $70 \% \mathrm{~B}: 30 \% \mathrm{D}$ & - & - \\
BD2 & - & $35 \% \mathrm{~B}: 65 \% \mathrm{D}$ & - & - \\
GS1 & - & $70 \% \mathrm{~A}: 30 \% \mathrm{~S}$ & - & - \\
GS2 & - & $35 \% \mathrm{~A}: 65 \% \mathrm{~S}$ & & - \\
\hline
\end{tabular}

\section{3. $X R F$}

Elemental analysis was performed on a Philips Magix PW2424 X-ray fluorescence analyzer using the X-ray tube made by rhodium target at a operating voltage of $50 \mathrm{kV}$ and working current of $50 \mathrm{~mA}$. Samples were prepared and analyzed according to the recommended manufacturer procedure.

\section{4. $X R D$}

XRD powder pattern was recorded on a Philips X'Pert Pro, the PW 3040/60 model with an X-ray tube PW 3373/00 Cu LFF DK119707 at a current of $40 \mathrm{~mA}$ and voltage of $40 \mathrm{kV}$, and goniometer PW $3050 / 60$. Recordings were made in the range $4-70^{\circ}(2 \theta)$. Again samples were measured according to the recommended manufacturer procedure.

\section{5. $P C A$}

PCA algorithm is a multidimensional data analysis tool that relies upon extracting the eigenvectors for the correlation matrix of the data matrix which contains the measured variables. PCA is used for investigating differences and similarities among sample's spectra through recognizing the pattern in the data matrix. Usually the first principal component (PC) accounts for the maximum variability within the data matrix and has the same direction as the eigenvector associated with the largest eigenvalue. Each succeeding component accounts for as much of the remaining variability as possible [1]. PCA models using two or three PCs can then be created to compare the spectra of all samples. In PCA models each cluster contains samples that have similar spectra and hence have similar composition, the farther the distance between clusters the more different they are [9]. MATLAB 7.0.4 (MathWorks, MA, USA) and PLS_Toolbox 4.0 (Eigenvector Research, Inc., WA, USA) were used for data processing and analysis. 


\section{Results and discussion}

\subsection{Elemental analysis using the ICP-OES and the XRF}

Elemental concentration of seven commercially available dental ceramics have been measured using wavelength dispersive X-ray fluorescence (WD-XRF) and inductively coupled plasma-optical emission spectroscopy (ICP-OES). Those two techniques work together as a complement to determine the major and trace constituents. The multi-element determination of the XRF method offers a simple way to analyze all samples for major elements. The trace constituents of the samples have been determined by ICP-OES after being digested. Major components of all dental ceramic types that are measured by $\mathrm{XRF}$ are presented in Table 2 except for type $\mathrm{S}$ because the prepared disc for sample $\mathrm{S}$ was so fragile and cracked upon cooling. Hence, only minor constituents for sample $\mathrm{S}$ were measured using the ICPOES. The major components of ceramic $\left(\mathrm{SiO}_{2}, \mathrm{Al}_{2} \mathrm{O}_{3}\right.$ and $\left.\mathrm{K}_{2} \mathrm{O}\right)$ are found in all samples in a weight percent of $>5 \%$. The weight percent of $\mathrm{SiO}_{2}$ ranged from 64.4 to $58 \%$, and that of $\mathrm{K}_{2} \mathrm{O}$ from 9.2 to $7.0 \%$. The weight percent of $\mathrm{Al}_{2} \mathrm{O}_{3}$ shows wide variability in the range $17-8.9 \%$. The sum of these three constituents ranged from 88.9 to $77.5 \%$. In addition to major elements, eighteen elements; $\mathrm{Ti}, \mathrm{Zr}, \mathrm{Ag}$, $\mathrm{Ba}, \mathrm{Cd}, \mathrm{Cr}, \mathrm{Cu}, \mathrm{Fe}, \mathrm{Mg}, \mathrm{Mn}, \mathrm{Na}, \mathrm{Ni}, \mathrm{P}, \mathrm{Pb}, \mathrm{S}, \mathrm{Sr}, \mathrm{V}$ and $\mathrm{Zn}$ have been detected by ICP. Table 3 sums up all elements detected by both XRF and ICP. According to their levels, elements were grouped into four different categories; major $(>5 \%)$, minor $(0.5-5.0 \%)$, trace $(0.05-0.50 \%)$ and ultra trace $(<0.05 \%)$. Ca and $\mathrm{Na}$ were detected in all samples and their concentrations ranged from 0.5 to $5.0 \%$. Concentrations of $\mathrm{Mg}$ were in the range 0.5 to $5.0 \%$ for samples $\mathrm{F}$ and $\mathrm{A}$, and $0.05-0.5 \%$ for the rest of samples. Levels

Table 2

Major components of dental ceramic samples that are detected by the XRF

\begin{tabular}{lcrrrrr}
\hline Component & \multicolumn{1}{c}{$\mathrm{A}$} & $\mathrm{B}$ & $\mathrm{D}$ & $\mathrm{F}$ & $\mathrm{G}$ & $\mathrm{H}$ \\
\hline $\mathrm{SiO}_{2}$ & 61.00 & 57.97 & 63.19 & 61.49 & 62.98 & 63.85 \\
$\mathrm{Al}_{2} \mathrm{O}_{3}$ & 15.07 & 13.89 & 16.09 & 8.91 & 15.82 & 17.03 \\
$\mathrm{~K}_{2} \mathrm{O}$ & 7.52 & 6.98 & 6.99 & 7.09 & 8.55 & 7.76 \\
$\mathrm{Na}_{2} \mathrm{O}$ & 3.34 & 4.00 & 4.97 & 5.01 & 3.53 & 4.42 \\
$\mathrm{CaO}$ & 1.40 & 2.18 & 0.77 & 1.79 & 2.04 & 0.67 \\
$\mathrm{MgO}$ & 0.53 & 0.13 & 0.59 & 3.31 & 0.27 & 0.09 \\
$\mathrm{TiO}_{2}$ & 0.08 & 0.43 & 0.03 & 0.02 & 0.42 & 0.02 \\
$\mathrm{MnO}$ & 0.03 & 0.03 & 0.03 & 0.03 & 0.04 & 0.04 \\
$\mathrm{P}_{2} \mathrm{O}_{5}$ & 0.03 & 1.40 & 0.01 & 0.01 & 0.09 & 0.03 \\
$\mathrm{Fe}_{2} \mathrm{O}_{3}$ & 0.01 & 0.01 & 0.00 & 0.02 & 0.02 & 0.02 \\
\hline
\end{tabular}

Table 3

Total concentration for all elements detected in all ceramic samples in this study using both the XRF and the ICP-OES

\begin{tabular}{lllll}
\hline Sample label & Major $(>5 \%)$ & Minor $(0.5-5 \%)$ & Trace $(0.05-0.50)$ & \multicolumn{1}{c}{ Ultra-trace $(<0.05 \%)$} \\
\hline $\mathrm{A}$ & $\mathrm{K}, \mathrm{Si}, \mathrm{Al}, \mathrm{Zr}$ & $\mathrm{Ca}, \mathrm{Mg}, \mathrm{Na}$ & $\mathrm{Fe}, \mathrm{Ti}, \mathrm{Mg}, \mathrm{Ba}, \mathrm{S}$ & $\mathrm{Mn}, \mathrm{P}, \mathrm{Ag}, \mathrm{Cr}, \mathrm{Cu}, \mathrm{Ni}, \mathrm{Pb}, \mathrm{Sr}, \mathrm{Zn}$ \\
$\mathrm{B}$ & $\mathrm{K}, \mathrm{Si}, \mathrm{Al}$ & $\mathrm{Ca}, \mathrm{P}, \mathrm{Na}$ & $\mathrm{Ti}, \mathrm{Mg}, \mathrm{Zr}, \mathrm{S}$ & $\mathrm{Fe}, \mathrm{Mn}, \mathrm{Ag}, \mathrm{Ba}, \mathrm{V}, \mathrm{Zn}$ \\
$\mathrm{D}$ & $\mathrm{K}, \mathrm{Si}, \mathrm{Al}$ & $\mathrm{Ca}, \mathrm{Na}$ & $\mathrm{Mg}, \mathrm{Zr}, \mathrm{S}$ & $\mathrm{Mn}, \mathrm{Ti}, \mathrm{P}, \mathrm{Ag}, \mathrm{Ni}, \mathrm{V}$ \\
$\mathrm{F}$ & $\mathrm{K}, \mathrm{Si}, \mathrm{Al}$ & $\mathrm{Ca}, \mathrm{Mg}, \mathrm{Na}$ & $\mathrm{S}$ & $\mathrm{Fe}, \mathrm{Mn}, \mathrm{Ti}, \mathrm{P}, \mathrm{Ag}, \mathrm{Zn}$ \\
$\mathrm{G}$ & $\mathrm{K}, \mathrm{Si}, \mathrm{Al}$ & $\mathrm{Ca}, \mathrm{Na}$ & $\mathrm{Ti}, \mathrm{Mg}, \mathrm{S}$ & $\mathrm{Fe}, \mathrm{Mn}, \mathrm{P}, \mathrm{Ag}, \mathrm{Ba}, \mathrm{Cu}, \mathrm{V}$ \\
$\mathrm{H}$ & $\mathrm{K}, \mathrm{Si}, \mathrm{Al}$ & $\mathrm{Ca}, \mathrm{Na}$ & $\mathrm{Ca}, \mathrm{Mg}, \mathrm{S}$ & $\mathrm{Fe}, \mathrm{Mn}, \mathrm{Ti}, \mathrm{P}, \mathrm{Ag}, \mathrm{Ba}, \mathrm{V}$ \\
$\mathrm{S}$ & $\mathrm{K}, \mathrm{Si}, \mathrm{Al}$ & $\mathrm{Ca}, \mathrm{Na}, \mathrm{Mg}$ & $\mathrm{S}$ & $\mathrm{Fe}, \mathrm{Ag}, \mathrm{Ti}, \mathrm{Mn}, \mathrm{Ba}, \mathrm{V}, \mathrm{P}$ \\
\hline
\end{tabular}


of $\mathrm{Zr}$ have shown wide variability in measured samples and ranged from major to ultra-trace levels. Maximum concentration for $\mathrm{Zr}$ was observed in sample A (8.2\%). The same high diversity was shown by the minor and trace elements in the long list of detected elements (Ag, Ti, Mn, Fe, Ba, S, Cr, Cu, Ni, $\mathrm{Pb}, \mathrm{V}, \mathrm{Zn}$ and $\mathrm{Sr}$ ) (Table 3). Some elements; such as, $\mathrm{Ag}, \mathrm{Ti}, \mathrm{Mn}, \mathrm{Fe}, \mathrm{Ba}$ and $\mathrm{S}$ were detected in most samples in trace to ultra-trace levels while the remaining elements $(\mathrm{Cr}, \mathrm{Cu}, \mathrm{Ni}, \mathrm{Pb}, \mathrm{V}, \mathrm{Zn}, \mathrm{Sr}, \ldots$, etc.) were detected in some samples and not detected in others. These might be some impurities that came from the raw materials used for the preparation of these samples. We believe that these impurities are not known to the producer, which might influence the materials' properties. The preparation of the fused disc for sample $S$ to be analyzed by XRF was not possible, which suggests that this sample has quit different physical properties than the rest of ceramic types.

\subsection{Assessment using $X R D$ and $P C A$}

XRD spectra for all samples (42 samples) were collected randomly. The XRD spectrum for each sample was recoded in an Excel file (counts versus $2 \theta$ ). The spectra for all samples were concatenated in a single Excel file of dimensions (5118 column $\times 42$ rows) using MATLAB 7.0.4. The XRD spectra were utilized for the purpose of comparing the spectra fingerprints of all ceramic samples (42 samples) that fall in seven types used in this study. All XRD data were background corrected. Figure 1 shows the XRD spectra for only three samples from three different ceramic types. As it can be seen, a visual comparison of these spectra which reflect the composition of these samples is very difficult, especially if more spectra were involved in the comparison. To differentiate the spectra efficiently, PCA was involved. Data were mean centered prior to PCA application. The total percentage of variances captured by the first four PCs were; 37.5, 11.3, 4.8 and 3.3\%, respectively. Only the first two PCs were used because they were the most significant. Figure 2 shows the resulted PCA score plot using the first and the second PC. Seven well resolved clusters can be recognized clearly in the model. Each cluster in the PCA model contains samples that belong to same type (source) of ceramic. Usually, in a PCA model the further the distance between clusters the more different their spectra are and hence, different chemical composition of these types of ceramic. Also it can be noticed from the PCA score model (Fig. 2) that both type A and type $G$ ceramics have much more similarities than the rest of the ceramic types investigated in

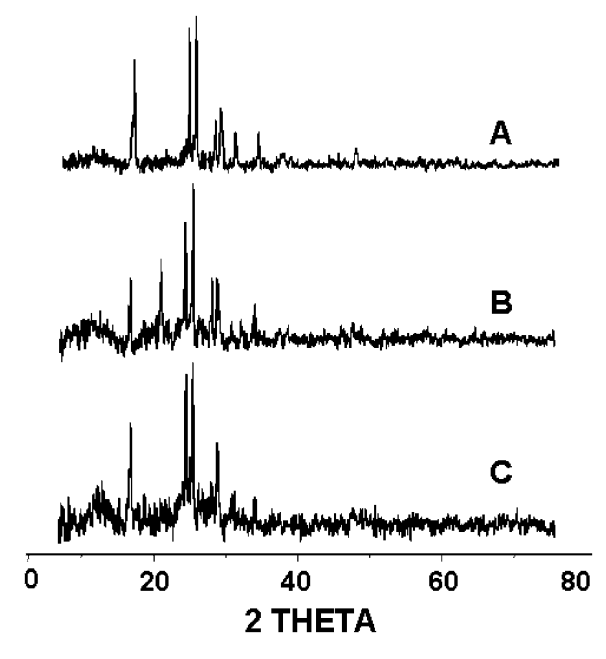

Fig. 1. XRD spectra for three ceramic types. 


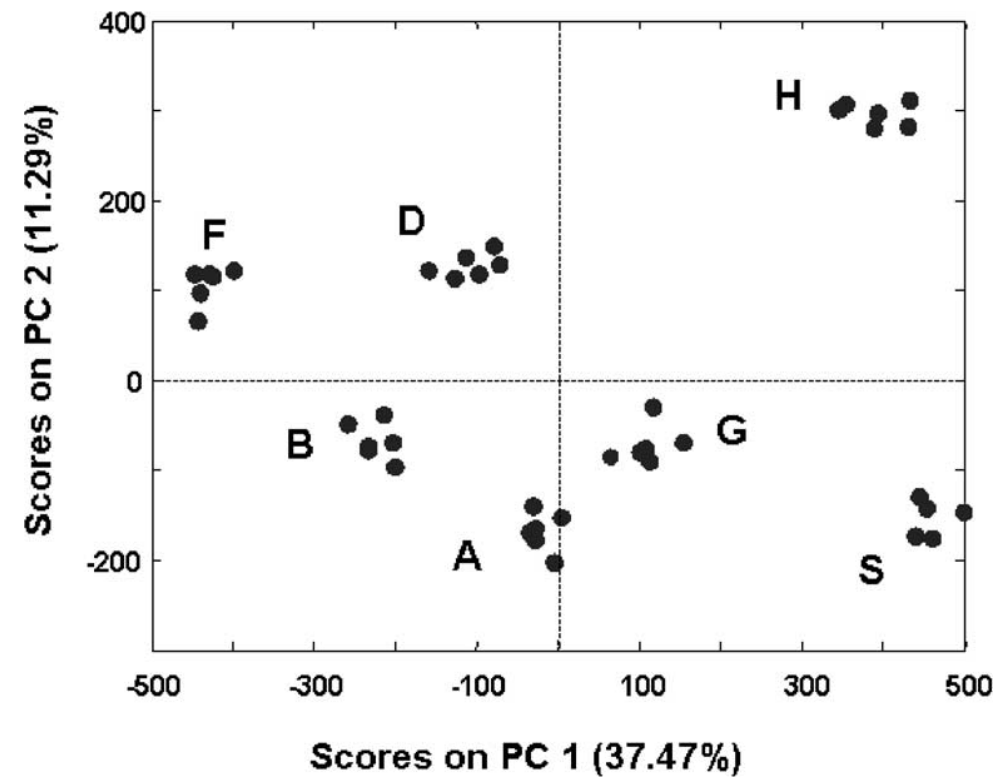

Fig. 2. PCA score plot applied on the XRD spectral data for seven types of dental ceramic (A, B, D, F, G, H, S).

this study. This means that they may have maximum spectral similarities, therefore, close chemical composition. On the other hand, the ceramic samples F, S and $\mathrm{H}$ have minimum similarities in chemical composition because their clusters seem to be the furthermost clusters in the PCA model. Fortunately, the distances between clusters of the expensive types (A, B and G) and the low-priced ones (F, S, H and D) seem to be good enough to detect adulterated samples that are composed of different ratios of these two price categories (Fig. 2). For the purpose of detecting possible adulteration in ceramics, the PCA model was used as a calibration model. The seven pure ceramic types and the created mixtures appear in Table 1. Each mixture was prepared using only two types of ceramics with two mass percentages (35:65 and 70:30). Four mixture samples of each ratio were created and analyzed by the XRD using the same instrumental conditions used for the pure ceramic samples. The data obtained from the XRD for the four mixture samples were concatenated in a new Excel file whose dimensions are (4 columns and 5118 rows). Figure 3, shows the result of applying the spectral data for the $(\mathrm{GH})$ mixtures to the original PCA model (Fig. 2). It is obvious from Fig. 3 that mixture samples of the similar ratios clustered together separately from the other clusters in the model. Moreover, the location of each of the mixture clusters is quit informative. For example in case of $(\mathrm{GH})$ mixtures, samples consisted of $70 \% \mathrm{G}(\mathrm{GH} 1)$ laid close to the $\mathrm{G}$ cluster and the one of $35 \%$ of $\mathrm{G}(\mathrm{GH} 2)$ laid closer to cluster $\mathrm{H}(\mathrm{GH} 2)$ reflecting the general ratio composition. The location of these mixtures between cluster $\mathrm{G}$ and $\mathrm{H}$ may suggest that they are consisted of these two ceramic types. The same story were obtained when applying the mixture samples of (GF) and (AF) where the mixture samples were clustered according to their mass ratios and between the clusters from which these mixture consisted of and always closer to the cluster of maximum contribution in the mixed samples. Unlike the above mixtures, the mixtures of (BD) required a third PC to best visualize the PCA model (Fig. 4). In this figure the new BD mixture samples behaved in a similar manner like (GF) and (AF) samples upon applying to the original PCA model in terms of the clustering and the location of the clusters. However, in case of (GS) mixed samples (GS1 and GS2) these samples form two independent clusters in the PCA model but the location of these mixtures was not informative (Fig. 5). However, this problem may be solved by inserting such clusters in the original 


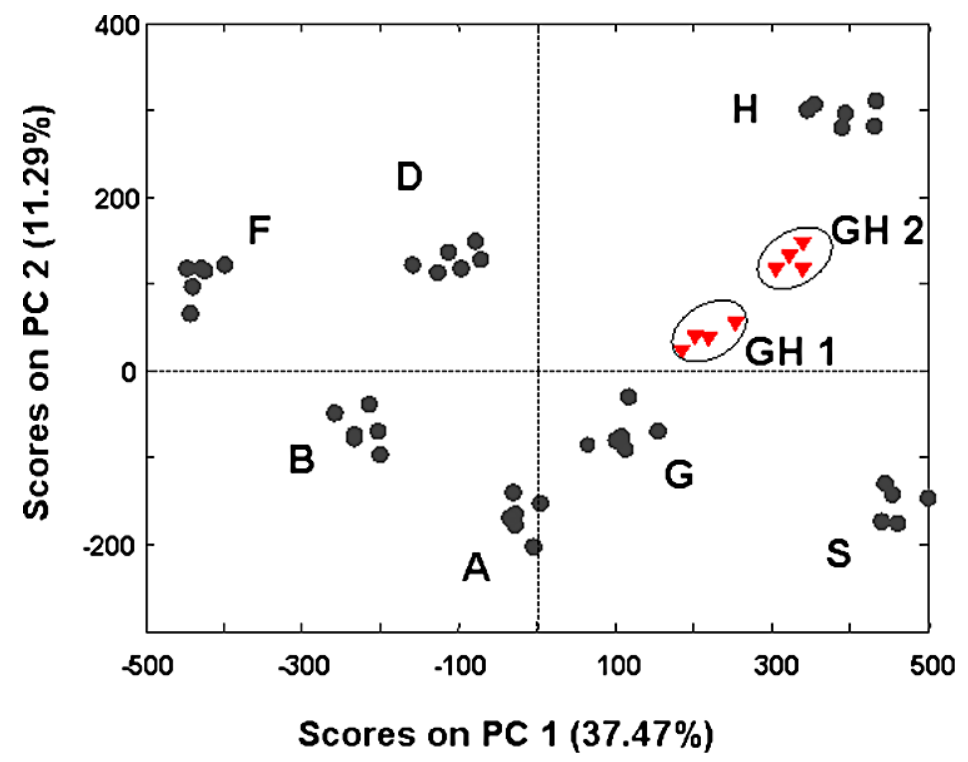

Fig. 3. PCA score plot showing the application of the obtained XRD data of mixture samples GH1 and GH2 (triangles) to the original PCA model (circles). (Colors are visible in the online version of the article; http://dx.doi.org/10.3233/SPE-2011-0521.)

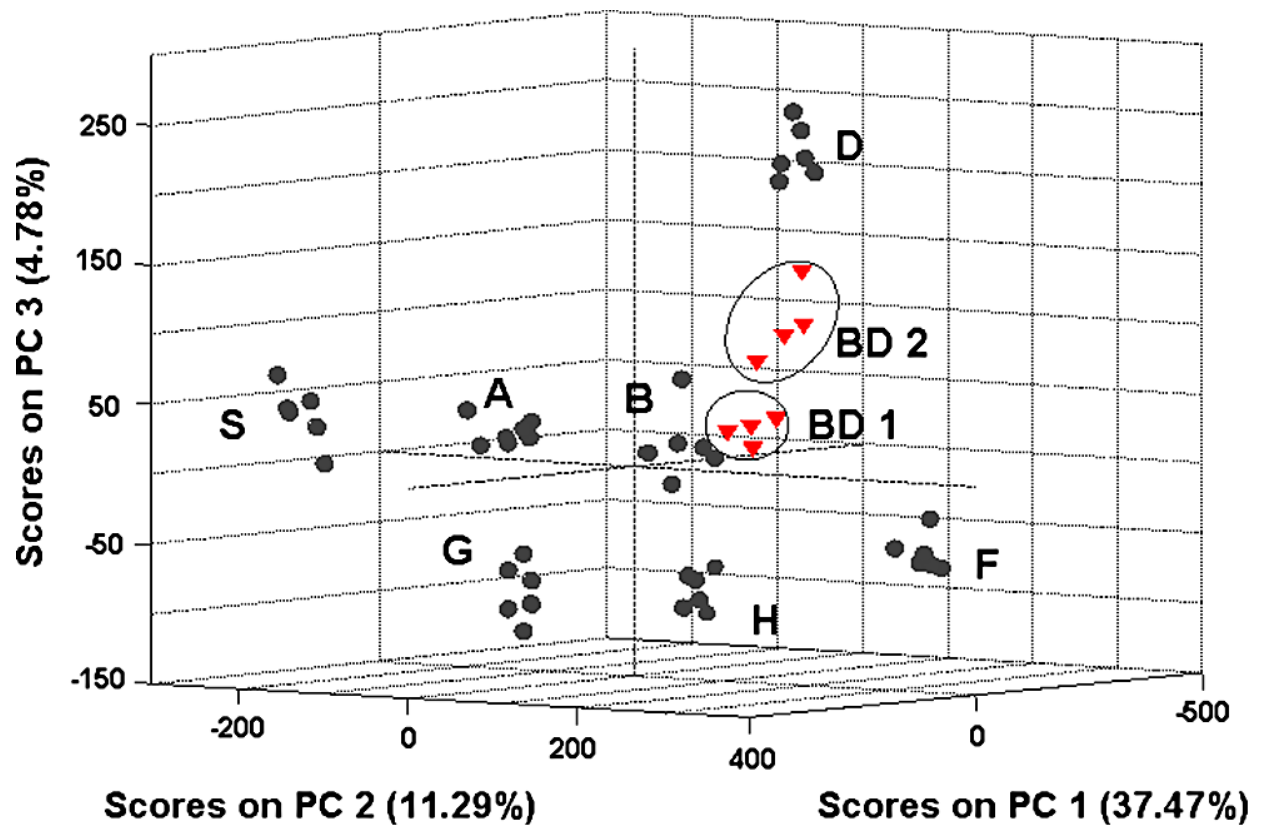

Fig. 4. PCA score plot showing the application of the obtained XRD data of mixture samples BD1 and BD2 (triangles) to the original PCA model (circles). (Colors are visible in the online version of the article; http://dx.doi.org/10.3233/SPE-2011-0521.)

PCA calibration model. In general, the mixed samples were clustered in independent clusters. Although the exact composition might be difficult to investigate using the PCA model, the independent clusters formed by the mixed samples present at least qualitative information about the sample and whether the sample is adulterated or not. 


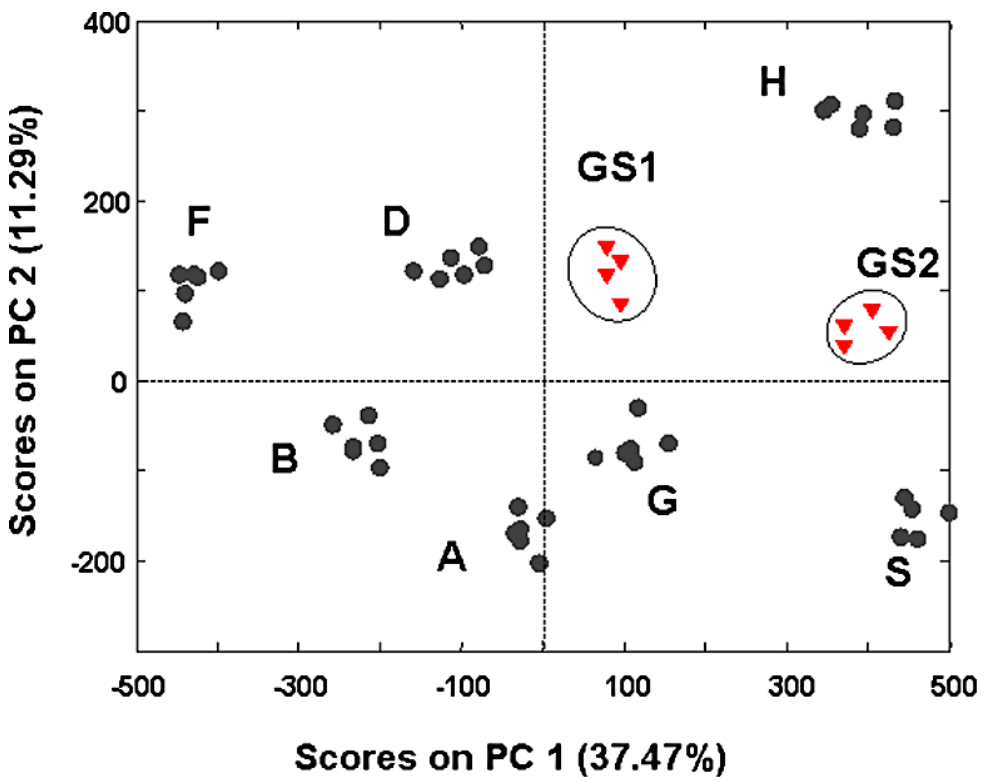

Fig. 5. PCA score plot showing the application of the obtained XRD data of mixture samples GS1 and GS2 (triangles) to the original PCA model (circles). (Colors are visible in the online version of the article; http://dx.doi.org/10.3233/SPE-2011-0521.)

\section{Conclusion}

In this study, the composition of the seven types of dental ceramics was investigated using both the ICP-OES and the XRF. The major components of ceramic $\left(\mathrm{SiO}_{2}, \mathrm{Al}_{2} \mathrm{O}_{3}\right.$ and $\left.\mathrm{K}_{2} \mathrm{O}\right)$ are found in all samples in a weight percent of $>5 \%$, which is in good agreement with the reported literature values [3]. Assessment of all ceramic samples was achieved successfully by applying PCA on the XRD data. Several ceramic mixtures that contain expensive and low-priced types of ceramics of different composition ratios were created in our laboratories to check the capability of the current technique to detect adulterated samples. Uncovering the adulteration in these samples was also promising. However, exact qualitative and quantitative determination of the adulterated samples may need further investigations or it can be solved by including mixtures (standard adulterated samples) with desired composition and ratios in the original PCA model.

\section{References}

[1] R.G. Brereton, Chemometrics: Data Analysis for the Laboratory and Chemical Plant, Hoboken, Wiley, 2005.

[2] J.L. Ferracane, Materials in Dentistry: Principles and Applications, 2nd edn, Lippincott Williams and Wilkins, MD, USA, 2001, pp. 159-170.

[3] R.A. Glenner and P. Willey, Filling materials in the confederacy, J. Hist. Dent. 46 (1998), 71-75.

[4] G.W. Ho and J.P. Matinlinna, Insights on ceramics as dental materials. Part I: ceramic material types in dentistry, Silicon 3 (2011), 109-115 (and references therein).

[5] J.G. Ironside and M.V. Swain, Ceramics in dental restorations - a review and critical issues, J. Aust. Ceram. Soc. 34(2) (1998), 78-91.

[6] E. Kontnonasaki et al., Microstructure characterization and comparative evaluation of physical, mechanical and biological properties of three ceramics for metal-ceramic restorations, Dent. Mater. 24 (2008), 1362-1373.

[7] J. Nicholson, The Chemistry of Medical and Dental Material, Royal Society of Chemistry, UK, 2002, pp. 63-70.

[8] R.V. Noort, Introduction to Dental Materials, 2nd edn, Elsevier, London, UK, 2002, pp. 233-238. 
[9] S. Obeidat, G. Rayson, B. Bai and D. Anderson, A multi-sourceportable LED spectrofluorometer, Appl. Spectrosc. 62 (2008), 327-332.

[10] J.B. Quinn, V. Sundar and I.K. Lioyd, Influence of microstructure and chemistry on the fracture toughness of dental ceramics, Dent. Mater. 19 (2003), 603-611.

[11] V.G. Sukumaran and N. Bharadwa, Ceramics in dental applications, Organs 20(1) (2006), 7-11.

[12] A.G. Wee, W. Chen and W.M. Johnston, Color formation and reproduction of opaque dental ceramic, Dent. Mater. 21 (2005), 665-670. 


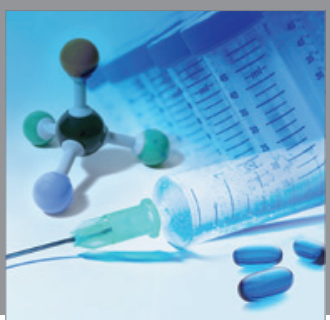

International Journal of

Medicinal Chemistry

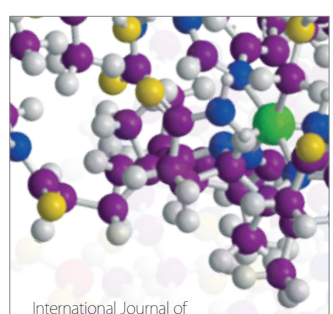

Carbohydrate Chemistry

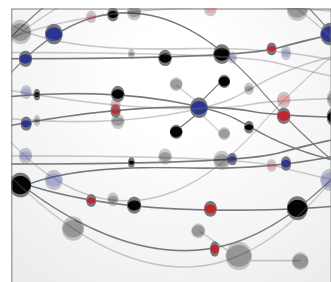

The Scientific World Journal
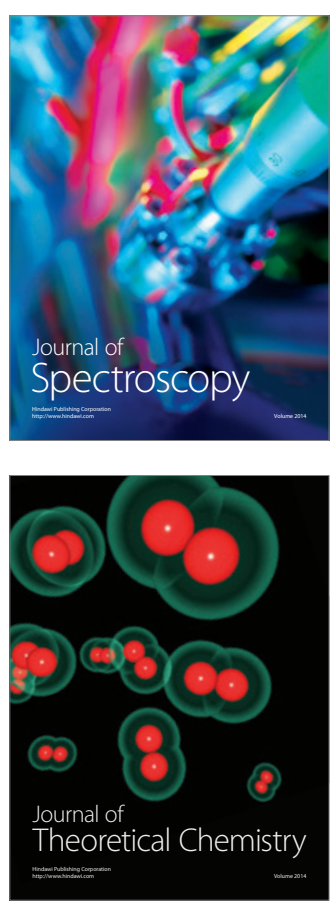
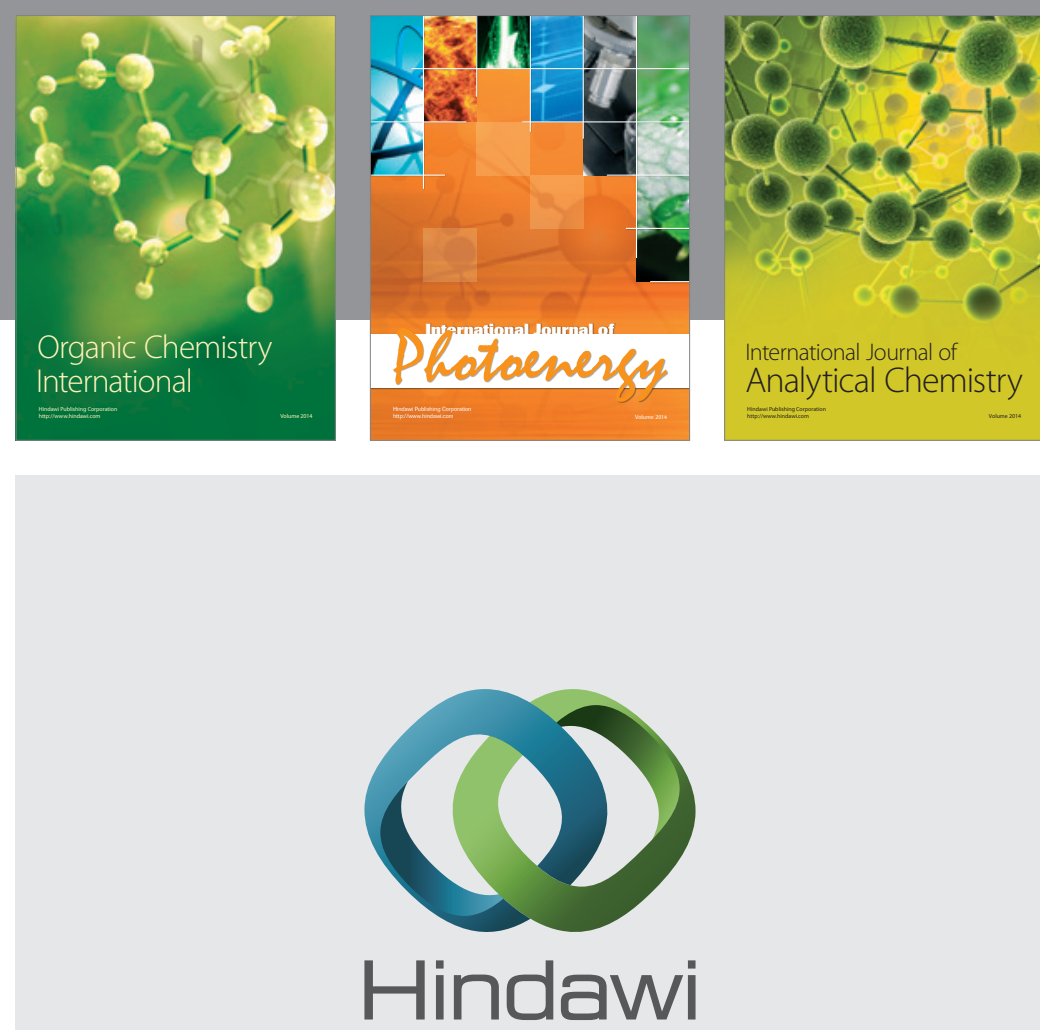

Submit your manuscripts at

http://www.hindawi.com
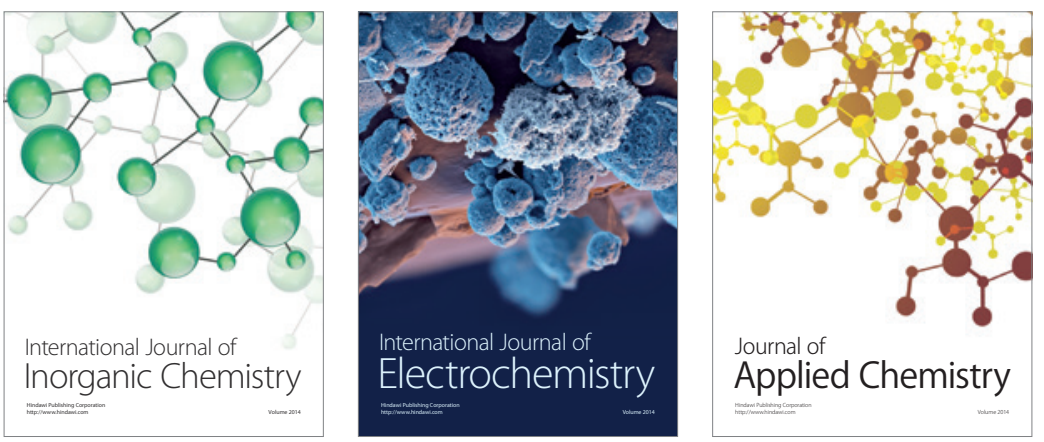

Journal of

Applied Chemistry
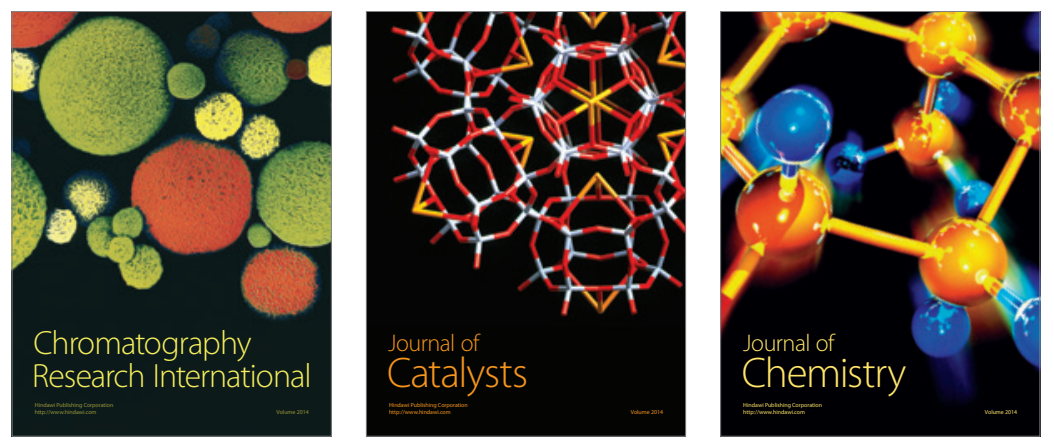
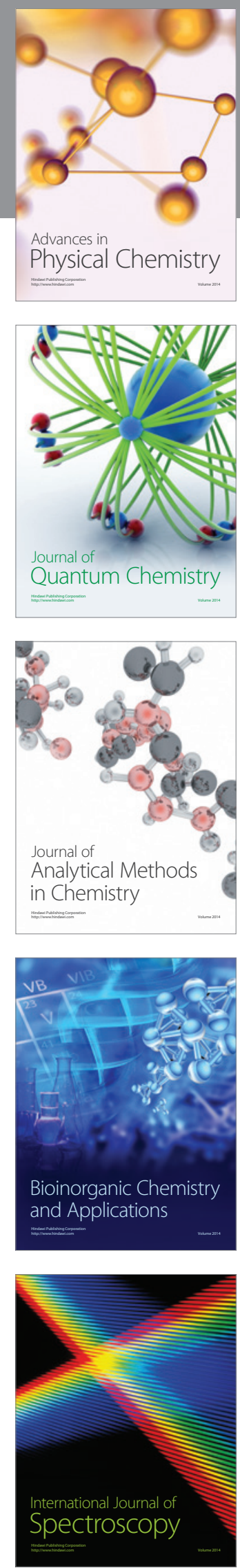